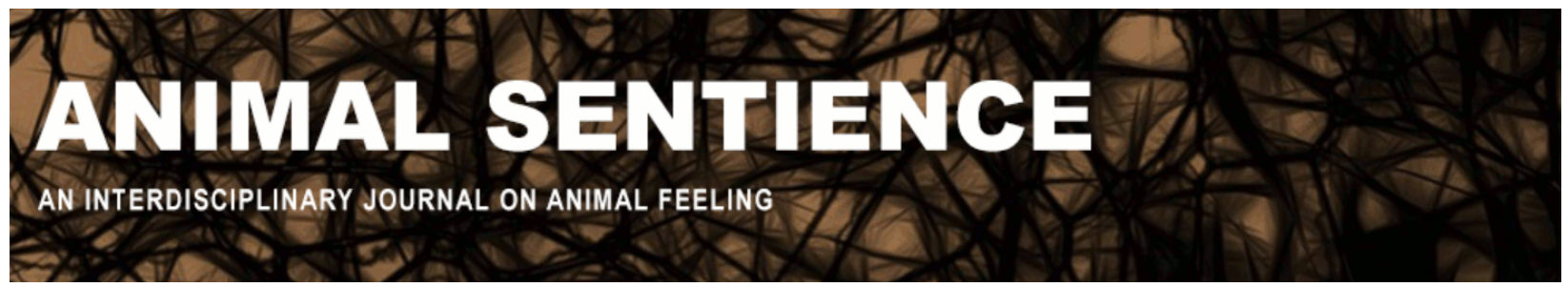

Atran, Scott (2019) Superior or inferior, human uniqueness is manifold. Animal Sentience 23(50)

DOI: $10.51291 / 2377-7478.1499$

Date of submission: 2019-06-28

Date of acceptance: 2019-07-11

(c)

This article has appeared in the journal Animal

Sentience, a peer-reviewed journal on animal

cognition and feeling. It has been made open access,

free for all, by WellBeing International and deposited

in the WBI Studies Repository. For more information,

please contact

wbisr-info@wellbeingintl.org.

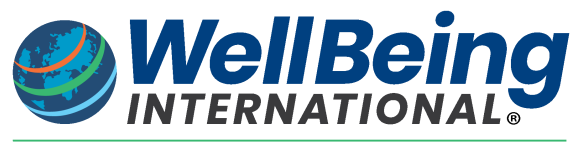

SOLUTIONS FOR PEOPLE, ANIMALS AND ENVIRONMENT 


\title{
Superior or inferior, human uniqueness is manifold
}

Commentary on Chapman \& Huffman on Human Difference

\author{
Scott Atran \\ School of Anthropology \& Changing Character of War Centre, University of Oxford \\ Department of Psychology \& Ford School of Public Policy, University of Michigan
}

\begin{abstract}
Chapman \& Huffman ( $\mathrm{C} \& \mathrm{H}$ ) contend that, as with all biological traits, there is evolutionary continuity underlying cognitive and social traits previously thought to be unique to humans. Yet C \& H, like Darwin, appeal to a seemingly unique moral aptitude that enables humans to be kind to conspecific strangers and other species.
\end{abstract}

\begin{abstract}
Scott Atran is Research Director Emeritus in Anthropology at France's National Center for Scientific Research, Research Professor of Psychology and Public Policy at the University of Michigan, Founding Fellow of the Centre for the Resolution of Intractable Conflict at the University of Oxford, and co-founder of ARTIS International. Website
\end{abstract}

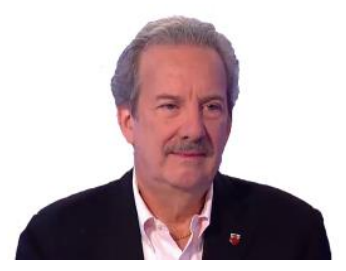

Chapman \& Huffman (2018) (C \& H) argue that claims about humans being unique almost invariably lead to beliefs about humans being superior to all other animals. C \& H acknowledge that "there are many differences (and similarities) between human and nonhuman species, just as there are differences (and similarities) between any two species, any two cultures, or even any two individuals. However, since all traits cannot be taken into account simultaneously, it is inappropriate to accord superiority to a subset of traits." They urge that we "use the traits we are so proud of - our vaunted intellect, communication skills, and morality - to create positive change." Here it is unclear whether C \& H consider each of these traits (or their combination), and the worthy cause that $\mathrm{C} \& \mathrm{H}$ want them to serve, to be unique or not. Or whether consideration of uniqueness, which for them is generally false, is always sinful.

Take the notion that animals have language: Syntactic structures involving "move-alpha" or the specified subject condition or unlimited recursion (or whatever apparent linguistic universal one selects) seem to have little to do with communication (but much to do with computational efficiency; Yang et al. 2017). Nothing remotely like these appears to arise in other creatures. And even if a specific trait might seem to have an analog or precursor in other animals, their combination into syntactic systems is incommensurably different from any putative analog or precursor (somewhat the way an automobile is an order of complexity different, in conceptual composition and material arrangement, from the sum of perfume sprayers, pulley-bearing shafts and so on that were the actual precursors of carburetors, crankshafts and so forth). With long, hard training and conditioning, you can get chimps to gesture a few concepts and put them in a regular sequential order. But this does not amount to 
language any more than if one were to train a human to jump up and down, higher and higher, and then claim humans can fly.

Or consider the willingness to self-sacrifice for an idea. Across cultures and history, humans make their greatest exertions, for ill or good, not for self or family, but for abstract ideas - causes that give life significance and seem worth preserving even more than life itself. This is the "privilege of absurdity to which no creature is subject, but man only" of which Hobbes wrote in Leviathan.

Indeed, in The Descent of Man, Darwin puzzled mightily over what would motivate "the bravest men, who were always willing to come to the front in war, and who freely risked their lives for others?" Since the brave were off risking (or reaching) death more than others, they would have fewer offspring on average: "therefore, it hardly seems probable that the number of men gifted with such virtues ... could be increased through natural selection, that is, by survival of the fittest" (Darwin 1871:163-165). Of course, Darwin acknowledged that the brave warrior who survives the fight will often gain more power or wealth or social worth or mates, and so improve the chances for reproducing healthy and successful offspring in greater numbers. But if the risk of death is very high, then it is highly doubtful that that gain would outweigh the loss.

How, then, could self-interest (or even genetic interest) account for the human aptitude for self-sacrifice to the point of giving one's life - the totality of one's self-interests - for one's tribe, nation, religion, humanity, the environment, or, indeed, "animal rights"? The puzzle led Darwin to modify his view that natural selection produces only selfish individuals. That view tends to disregard the remote consequences of actions motivated by what Darwin deemed "highly esteemed, even sacred" spiritual and moral virtues that "give an immense advantage" to one group over another when possessed by devoted actors who "by their example excite ... in a high degree the spirit" in others to self-sacrifice. Here, Darwin suggests a naturally-selected propensity toward moral virtue that leads to willingness to sacrifice self-interest for group interest. When a perceived outside threat to one's primary reference group is very high, and survival prospects very low, if sufficiently many members of a group are endowed with this willingness to make the extreme sacrifice, the group may resist stronger but less devoted enemies who are less committed to disregarding costs of action.

Humans are above all moral animals because they are creatures who can love their (kin or non-kin) group even more than they love themselves. But not only the group: Although groups and causes (i.e., ideas and beliefs that give significance to life) often go together (and their interaction maximizes willingness to sacrifice), identity fusion with a group and devotion to a cause are independent predictors of willingness to self-sacrifice (Sheikh, Gómez and Atran 2016). When push comes to shove (in forced-choice experiments as well as in actual behavior on the battlefield; Gómez et al. 2017), people will forsake family or tribe (or any group with which they identify with) for a cause if they believe their group has forsaken values held "sacred": that is, immune to material tradeoffs, social pressures, temporal and spatial discounting, and so on (whether the values are secular, like The Nation, or religious, like The Holy Land; Atran and Ginges 2012).

Sacred values determine which social and material transactions are morally proper or taboo; they can drive actions in intergroup conflict independently of material interests or consequences. Examples include decisions to initiate or sustain war, with religiously motivated suicide bombers willing to die to broadcast commitment regardless of whether others are killed. 
Another example is certain Native American groups rejecting majority-culture offers for overexploiting natural resources (including animals) as violations of spiritual injunctions, even though such laudable resistance hastens these indigenous peoples' own extinction in today's open-access commons (Atran and Medin 2008).

As shown by sociological and ethnographic studies (Rappaport 1971) as well as behavioral and brain studies (on indigenous populations in the Americas, on the battlefield in the Middle East, on radicalized individuals in Europe [Pretus et al. 2018], and on a sample of majority-culture Americans [Berns et al. 2012]), sacred values and preferences are processed very differently from mundane values. They lead to very different sorts of behavior, including self-sacrifice for no one or no group in particular. This does not appear to have the faintest echo in the rest of the animal world.

For Alfred Russel Wallace (1899), co-discoverer of the theory of evolution by natural selection, moral behavior (along with mathematics, music, and art) was evidence that humans, unlike all other animals, had not evolved through natural selection alone:

"The special faculties we have been discussing clearly point to the existence in man of something which has not derived from his animal progenitors - something which we may best refer to as being of a spiritual essence ... beyond all explanation by matter, its laws and forces." (475-476)

Needless to say, Wallace's account of self-sacrifice for group or cause as a spiritual creation beyond all material explanation did not sit well with Darwin's empirical bent of mind: "I hope you have not murdered too completely your own and my child," lamented Darwin (1903:39) in a letter to Wallace. Yet Darwin himself produced no causal account of how love of group or cause might have emerged. (For a critique of neo-Darwinian group selection theory and the question of whether complex cultural practices such as religion are evolutionary adaptations, see Atran 2004). Nor did Darwin give good reasons why natural selection should have produced truly selfless devotion only in humans, other than to say that because our ancestors were so physically weak, only group strength could get them through. Here Darwin intimates that nonhuman animals can be superior in some respects, whereas humans can still be unique in myriad others.

\section{References}

Atran, S. (2004) In Gods We Trust: The Evolutionary Landscape of Religion. New York: Oxford University Press.

Atran, S., and Ginges, J. (2012) Religious and sacred imperatives in human conflict. Science, 336, 855-857.

Atran, S., and Medin, D. (2008) The Native Mind and the Cultural Construction of Nature. Cambridge, MA: MIT Press.

Berns, G., Bell, E., Capra, C. M., Prietula, M., Moore, S., Anderson, B., Ginges, J., and Atran, S. (2012) The price of your soul: Neural evidence for the non-utilitarian representation of 
sacred values. Philosophical Transactions of the Royal Society of London B: Biological Sciences, 367, 754-762.

Chapman, C.A., and Huffman, M.A. (2018) Why do we want to think humans are different? Animal Sentience, 23(1).

Darwin C. (1871) The descent of man, and selection in relation to sex. London: John Murray, pp. 163-165.

Darwin, C. (1903) More letters of Charles Darwin (Vol. 2). London: John Murray.

Gómez, Á., López-Rodríguez, L., Sheikh, H., Ginges, J., Wilson, L., Waziri, H., Vázquez, A., Davis, R., and Atran, S. (2017) The devoted actor's will to fight and the spiritual dimension of human conflict. Nature Human Behaviour, 1, 673-679.

Pretus, C., Hamid, N., Sheikh, H., Ginges, J., Tobeña, Davis, R., Vilarroya, O., and Atran, S. (2018) Neural and behavioral correlates of sacred values and vulnerability to violent extremism. Frontiers in Psychology, 9.

Rappaport, R. (1971) The sacred in human evolution. Annual Review of Ecology and Systematics, 2, 23-44.

Sheikh, H., Gómez, Á., and Atran, S. (2016) Empirical evidence for the devoted actor model. Current Anthropology, 57(S13), 204-209.

Wallace, A. R. (1899) Darwinism. London: Macmillan.

Yang, C., Crain, S., Berwick, R. C., Chomsky, N., and Bolhuis, J. J. (2017) The growth of language: Universal grammar, experience, and principles of computation. Neuroscience \& Biobehavioral Reviews, 81, 103-119. 